\title{
PREPARAÇÃO DE FILMES BIODEGRADÁVEIS DE AMIDO DE MANDIOCA PELO MÉTODO TAPE-CASTING E COM SECAGEM AO SOL.
}

\author{
BORGES, A. L. G ${ }^{1}$; LAURINDO, J. B. ${ }^{2}$, SCHMIDT, V. C. R. ${ }^{3}$ \\ ${ }^{1}$ Laboratório de Engenharia de Alimentos, FEQUI, Universidade Federal de Uberlândia, \\ E-mail: analuizaguimaraesborges@ufu.br \\ ${ }^{2}$ Laboratório de Propriedades Físicas de Alimentos, UFSC, Universidade Federal de Santa \\ Catarina, E-mail: jb.laurindo@ufsc.br; \\ ${ }^{3}$ Laboratório de Engenharia de Alimentos, FEQUI, Universidade Federal de Uberlândia, \\ E-mail: vivianfeq@ufu.br,
}

\section{RESUMO}

O interesse no emprego de matérias-primas provenientes de recursos renováveis para a produção de embalagens de alimentos vem crescendo ano a ano, dentre os biopolímeros mais promissores para este fim estão os amidos, além de serem biodegradáveis, têm custo baixo e estão disponíveis em todo o mundo. O objetivo deste projeto foi desenvolver o preparo e a caracterização dos filmes biodegradáveis de amido de mandioca utilizando o equipamento com o método tape-casting e com secagem ao sol. Este método é interessante, pois permite a obtenção de filmes com maiores dimensões, podendo ser utilizado, como exemplo, para confecção de sacolas, embalagens e filmes para agricultura. 


\section{Congresso Brasileiro de Engenharia Química \\ em Iniciação Científica \\ UFSCar - São Carlos - SP \\ 16 a 19 de Julho de 2017}

\section{INTRODUÇÃO}

A demanda por materiais plásticos produzidos a partir de fontes renováveis tem experimentado um crescimento contínuo tanto em função de interesses econômicos quanto por razões ambientais. Apesar de ainda apresentar custos de produção superiores aos polímeros convencionais, estes materiais designados como biodegradáveis ou verdes, têm sido objeto de extensas pesquisas e avaliações.

O amido se destaca na elaboração de biopolímeros, pois ele alia o manejo do ciclo de carbono com disponibilidade, preço baixo e desempenho aceitável para algumas aplicações (WILHELM, H.M et al, 2003). .

Biofilmes a base de amido apresentam boas propriedades de barreira a gases como $\mathrm{O}_{2}$ e $\mathrm{CO}_{2}$ e ao óleo. Entretanto, a grande limitação destes materiais está nas propriedades mecânicas inferiores a dos filmes convencionais e à alta permeabilidade ao vapor de água que eles apresentam (GONTARD et al, 2006).

Sendo assim, diversos estudos têm sido realizados utilizando o amido para a formação de embalagens biodegradáveis (MORAES, J. O. 2009; COVA, A. et al, 2010). Uma técnica ainda pouco difundida para elaboração de filmes biodegradáveis é a tape-casting ou spreadcasting.

A técnica consiste no espalhamento controlado de uma suspensão, em uma superfície, para posterior secagem. Essa técnica é difundida na indústria de papel e cerâmica e pode ser utilizada para a preparação de filmes finos de dimensões muito superiores às dos filmes preparados pelo método de casting tradicional.

Neste contexto, a secagem ao sol é um dos métodos mais antigos de conservação de alimentos A linha de trabalho sobre a secagem solar surgiu da necessidade de garantir um melhor aproveitamento da produção agrícola e, consequentemente, a melhoria da qualidade de vida dos agricultores por meio da utilização de energias renováveis.

Diante do exposto, o objetivo deste trabalho foi relacionado com a preparação e caracterização de filmes de amido de mandioca e filmes de acetato de amido com a utilização do método tape-casting avaliando três diferentes tipos de secagem para cada filme bem como a resistência dos filmes em relação a orientação da matriz. 


\section{MATERIAIS E METODOS}

\subsection{MATERIAIS}

O amido foi obtido no comércio local, nesse caso, utilizamos o Amido de Mandioca (Yoki Alimentos S.A.). Para a produção de filmes foi utilizado o Glicerol P.A.(Synth). Para a produção do acetato de amido foram utilizados o Anidrido Acético P.A. (Vetec), Ácido Acético P.A.(Dinâmica) e Ácido Sulfúrico P.A. (Synth), goma Guar (Prymer Foods).

\subsection{MÉTODOS}

\subsubsection{Caracterização do amido de mandioca}

Preliminarmente o amido de mandioca foi caracterizado por análises físico-químicas para homogeneizar as amostras utilizadas durante o projeto. As análises realizadas foram: umidade, cinzas e teor de amilose.

\section{Umidade}

A umidade do amido de mandioca foi determinado pelo método gravimétrico 925.10 sugerido pela AOAC (1995), através do qual a água evaporada em estufa com circulação de ar a $105^{\circ} \mathrm{C}$.

\section{Cinzas}

As cinzas foram determinadas segundo a técnica 923.03 da AOAC (1995) que consiste na queima do material em bico de Bunsen e incineração completa da amostra a 550 ${ }^{\circ} \mathrm{C}$. 


\section{Congresso Brasileiro de Engenharia Química \\ em Iniciação Científica \\ UFSCar - São Carlos - SP

Teor de amilose

O teor de amilose do amido foi determinado pela técnica colorimétrica de WILIAMS et al. (1970). Amostras de $20 \mathrm{mg}$ de amido, foram dispersas em $10 \mathrm{~mL}$ de hidróxido de sódio 1N; diluídas 10 vezes com posterior adição de ácido clorídrico 0,2 N e solução I-KI (iodo, iodeto de potássio). A leitura foi realizada em espectrofotômetro marca Hitachi depois, modelo U1800, UV visível, a $680 \mathrm{~nm}$. O teor de amilose foi obtido a partir da curva padrão com o emprego de amilose e amilopectina de mandioca extraída a partir da mandioca (MCCREADY e HASSID, 1943).

\subsubsection{Preparo do filme}

Para obtenção da supensão de amido nativo de mandioca foram pesados $4 \mathrm{~g}$ de amido/g de solução e 0,30 g de glicerol/g de amido em uma balança semi-analítica (marca Shimadzu). Em seguida, a suspensão foi aquecida em banho ultra termostatizado (marca Solab), sob agitação mecânica. Após a solução atingir $75^{\circ} \mathrm{C}$, foi mantida por 5 minutos, para gelatinização completa do amido. Após o processo, a solução foi despejada sobre o equipamento pelo método tape-casting e arrastada pela lamina de espalhamento doctorblade, conforme a figura 1.

Para a elaboração dos filmes a lamina de espalhamento doctor-blad foi ajustada a uma distância de $140 \mu \mathrm{m}$ da placa de alumínio superior.

Figura 1 - Equipamento de secagem pelo método tape-casting

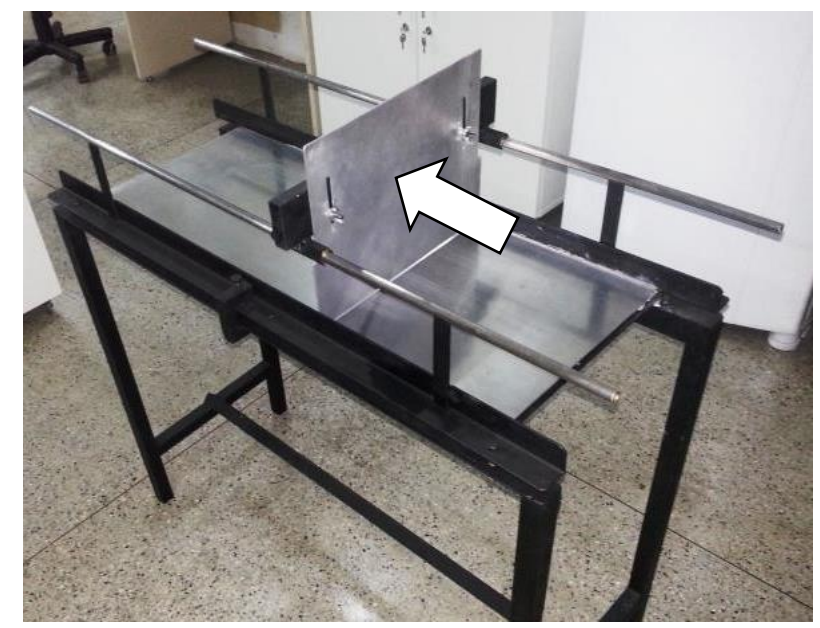




\section{Congresso Brasileiro de Engenharia Química \\ em Iniciação Científica \\ UFSCar - São Carlos - SP \\ 16 a 19 de Julho de 2017}

\subsubsection{Secagem dos filmes}

Os filmes foram submetidos à secagem no equipamento com aquecimento apenas na parte inferior e com secagem ao sol, até que a umidade de equilíbrio seja atingida.

Durante a secagem dos filmes foram avaliados: a temperatura da placa inferior, a temperatura na superfície do filme exposto ao sol bem como o tempo de secagem utilizado.

\subsubsection{Caracterização dos Filmes}

\section{Testes Mecânicos}

Para determinar as propriedades mecânicas dos filmes foram realizados testes de tração no material (tensão na ruptura, alongamento na ruptura e Módulo Young) usando o analisador de textura (texturômetro) TA-XT2i Stable Micro System (SMS, Surrey, Inglaterra). As amostras para o teste mecânico foram cortadas em dimensões de $25 \mathrm{~mm}$ por $100 \mathrm{~mm}$ (conforme figura 4) e ajustadas às garras do equipamento, cuja distância inicial era de $100 \mathrm{~mm}$. A velocidade de tração de $0,8 \mathrm{~mm} / \mathrm{s}$. A figura 2 apresenta o equipamento texturômetro com corpo de prova.

Figura 2 - Texturômetro.

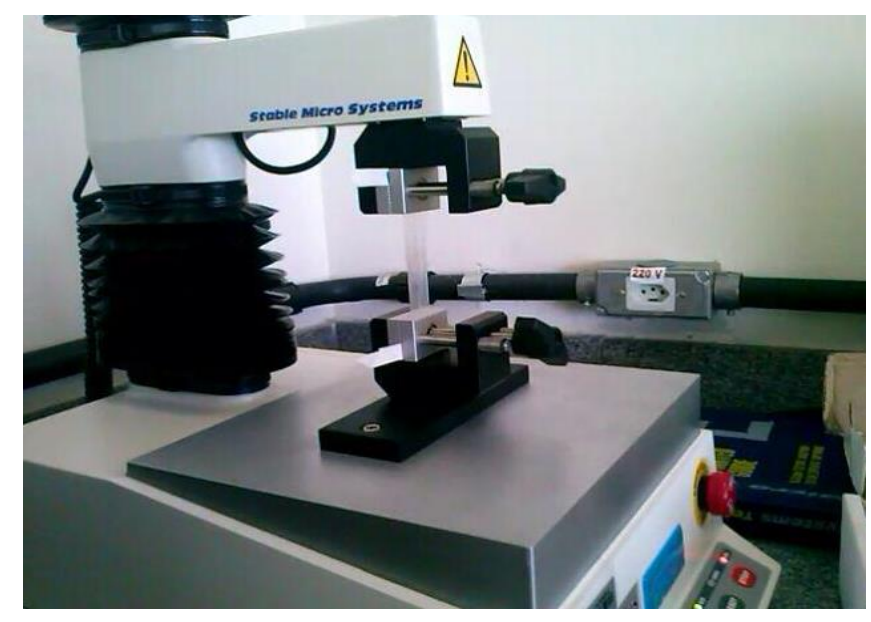




\section{Congresso Brasileiro de Engenharia Química \\ em Iniciação Científica \\ UFSCar - São Carlos - SP \\ 16 a 19 de Julho de 2017}

\section{Condicionamento dos Filmes}

Antes dos testes mecânicos, os filmes foram acondicionados por 5 dias em ambiente climatizado a $25{ }^{\circ} \mathrm{C}$ e umidade relativa de $58 \%$ (solução saturada de brometo de sódio P.A, $\mathrm{NaBr}$ ). A figura 3 apresenta as amostras nas dimensões 25x100 mm, dimensões necessárias para o teste de tração na ruptura, E a figura 4 os filmes já condicionados.

Figura 3 - Filmes antes de serem submetidos ao acondicionamento.

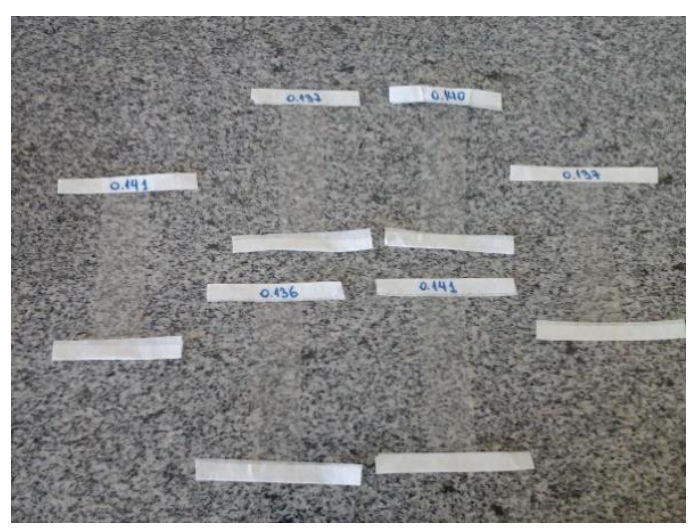

Figura 4 - Acondicionamento dos filmes

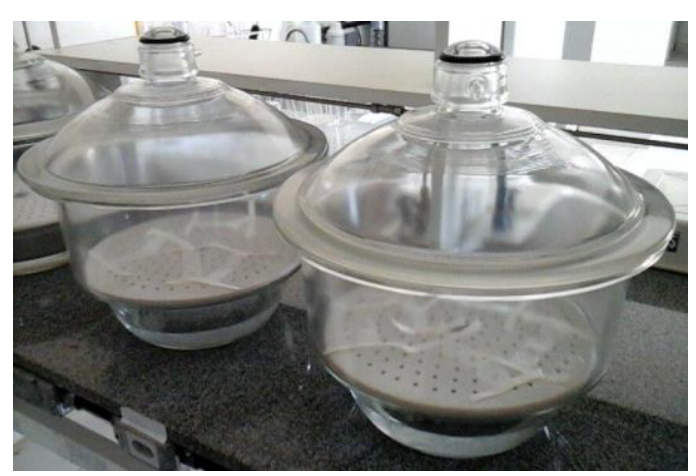

\section{RESULTADOS E DISCUSSÕES}

\subsection{CARACTERIZAÇÃO DO AMIDO DE MANDIOCA}

Os resultados das análises físico-químicas do amido de mandioca nativo utilizado neste trabalho são apresentados na tabela 1 . 
Conforme observado na tabela 1 , o valor de teor de umidade encontrado para as amostras de amido nativo foram de $11,59 \pm 0,11 \mathrm{~g} \cdot 100 \mathrm{~g}^{-1} \mathrm{e}$ a de cinzas de $0,15 \pm 0,001 \mathrm{~g} \cdot 100 \mathrm{~g}^{-1}$, respectivamente. Os valores de teor de umidade estão em conformidade com a legislação que para o MAPA (2005), os valores para umidade são de até 14\% e cinzas de até 0,20\% e para ANVISA (2005), o valor do teor de umidade é de, no máximo, $18 \%$ e de cinzas de $0,50 \%$.

Tabela 1. Características físico-químicas das amostras de amido de mandioca nativo.

\begin{tabular}{|c|c|c|c|}
\hline $\begin{array}{c}\text { Teor de Umidade } \\
(\mathrm{g} / 100 \mathrm{~g})\end{array}$ & $\begin{array}{c}\text { Cinzas } \\
(\mathrm{g} / 100 \mathrm{~g})\end{array}$ & $\begin{array}{c}\text { Teor de Amilose } \\
(\%)\end{array}$ & $\begin{array}{c}\text { Densidade } \\
\text { Absoluta }(\mathrm{g} / \mathrm{mL})\end{array}$ \\
\hline $11,59 \pm 0,11$ & $0,15 \pm 0,001$ & $18,02 \pm 1,75$ & $1,68 \pm 0,06$ \\
\hline
\end{tabular}

\subsection{FILMES DE AMIDO}

\subsubsection{Secagem dos Filmes}

Nesta etapa, os resultados dos filmes que foram preparados e secos no equipamento pelo método tape-casting figura 1. Foram avaliados outros parâmetros de secagem, como o tempo e as características dos filmes de amido, conforme o apresentado nas tabelas 2 e 3 .

Tabela 2. Temperaturas de secagem.

\begin{tabular}{|l|c|c|c|}
\hline \multirow{2}{*}{ Forma de secagem } & \multicolumn{3}{|c|}{ Temperatura $\left({ }^{\circ} \mathrm{C}\right)$} \\
\cline { 2 - 4 } & $\begin{array}{c}\text { No equipamento } \\
\left({ }^{\circ} \mathrm{C}\right)\end{array}$ & $\begin{array}{c}\text { Na superfície } \\
\left({ }^{\circ} \mathrm{C}\right)\end{array}$ & $\begin{array}{c}\text { No banho } \\
\left({ }^{\circ} \mathrm{C}\right)\end{array}$ \\
\hline Aquecimento na parte inferior e ao sol & $47 \pm 1,2$ & $53 \pm 1,5$ & $87 \pm 1$ \\
\hline
\end{tabular}

Tabela 3. Parâmetros de secagem dos filmes de amido nativo.

\begin{tabular}{|c|c|c|}
\hline Forma de secagem & Tempo de secagem & $\begin{array}{c}\text { Aspecto do filme após o tempo } \\
\text { de secagem. }\end{array}$ \\
\hline Aquecimento na parte inferior e ao sol & 4 a 5 horas & Fácil manuseio \\
\hline
\end{tabular}




\section{Congresso Brasileiro de Engenharia Química \\ em Iniciação Científica \\ UFSCar - São Carlos - SP 16 a 19 de Julho de 2017}

Os filmes de amido nativo secos apenas com aquecimento na parte inferior do equipamento mostraram um tempo de secagem de 6 a 7 horas, na secagem com aquecimento inferior, o mesmo foi realizado pela circulação de água do banho a $87^{\circ} \mathrm{C}$, porém houve perda de calor transferido para a superfície de secagem, sendo a temperatura atingida de aproximadamente $53^{\circ} \mathrm{C}$.

Já os filmes submetidos à secagem ao sol tiveram o tempo de secagem de 5 a $8 \mathrm{~h}$.

O método com aquecimento na parte inferior e com secagem ao sol obteve filmes com tempo de secagem um pouco menor quando comparados aos demais métodos testados (aproximadamente 5h), sendo assim, o mais adequado nas condições realizadas.

\subsubsection{CARACTERIZAÇÃO DO FILME}

Os filmes de amido de mandioca obtidos pelo método de tape-casting foram homogêneos, brilhantes e transparentes, e com fácil manuseio, conforme apresentado na figura 5 .

Figura 5. Filmes de amido obtidos pelo método tape-casting.

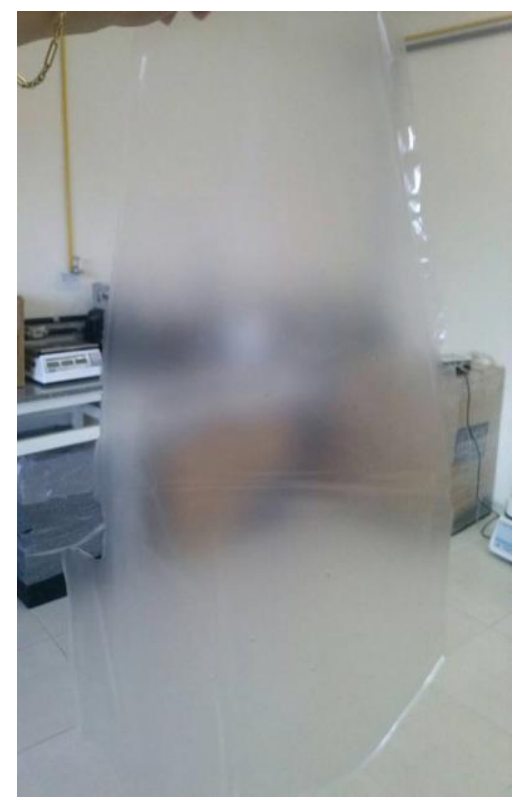




\section{Congresso Brasileiro de Engenharia Química \\ em Iniciação Científica \\ UFSCar - São Carlos - SP \\ 16 a 19 de Julho de 2017}

Antes da realização dos testes de tração, os filmes de amido foram condicionados às umidades relativas (UR) de $58 \%(\mathrm{NaBr})$ por 5 dias. Os resultados de tensão, alongamento na ruptura e módulo de Young dos filmes de amido nativo são apresentados nas tabelas 4.

Tabela 4. Tensão na ruptura, alongamento e módulo de Young dos filmes de amido de mandiocar nativo.

\begin{tabular}{|l|l|l|l|l|}
\hline Forma de secagem & $\begin{array}{c}\text { Espessura } \\
\text { média }(\boldsymbol{\mu m})\end{array}$ & $\begin{array}{c}\text { Tensão na } \\
\text { ruptura TS } \\
(\mathbf{M P a})\end{array}$ & $\begin{array}{c}\text { Alongamento } \\
\text { na ruptura } \\
(\boldsymbol{\%})\end{array}$ & $\mathbf{Y}(\mathbf{M P a} / \%)$ \\
\hline $\begin{array}{l}\text { Aquecimento na } \\
\text { parte inferior e ao sol }\end{array}$ & $145 \pm 5,00$ & $17,92 \pm 1,36$ & $64,00 \pm 3,70$ & $0,33 \pm 0,01$ \\
\hline
\end{tabular}

Os filmes de amido nativo de mandioca com secagem apenas pelo sol apresentaram valores menores de alongamento na ruptura $(23,43 \pm 0,99 \%)$ quando comparados com os filmes de amido nativo submetidos à secagem com aquecimento na parte inferior e aquecimento com secagem na parte inferior e com o sol, isto pode ser explicado por este filme apresentar uma espessura menor quando comparados com os demais testes.

Para os filmes dos testes com secagem na parte inferior e secagem na parte inferior e ao sol não apresentaram valores de tensão, alongamento na ruptura e módulo de Young com diferenças significativas a nível de 5\%. Assim, não houve diferença nas propriedades mecânicas avaliando estes dois tipos de secagem.

Pode ser observado que os valores de tensão na ruptura para os tipos de secagem ficaram bem próximos. Isto significa que não tiveram diferença significativa ao nível 5\%. Assim, a forma de secagem não influenciou nas propriedades mecânica deste tipo de filme.

Segundo SCHMIDT (2012) que trabalhou com preparação e caracterização de filmes de amido modificado por reticulação, acetilação e com adição de lipídio e celulose bacteriana,

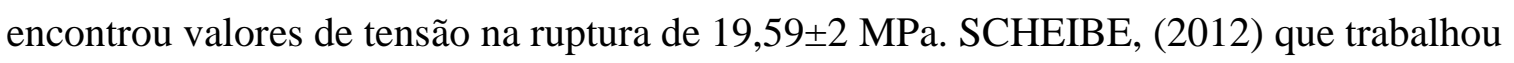
produção e caracterização de embalagem biodegradável de amido de mandioca e fibras usando a técnica de tape-casting referenciou valores diferentes nas propriedades mecânicas para filmes de amido com fibra. Esta autora apresentou valores de 11,08 $\pm 5 \mathrm{MPa}$ para tensão na ruptura. Já MORAES (2013) que trabalhou produção e caracterização de filmes de amidoglicerol-fibras de celulose elaboradas por tape-casting, apresentou resultados de tensão na ruptura de $23,01 \pm 19$. 
Sendo assim, os filmes de amido nativo obtidos mostraram de modo geral ter boas propriedades mecânicas.

\section{CONSIDERAÇÕES FINAIS}

Os resultados apresentados nestes trabalhos apresentaram que os filmes a base de amido possuem boas propriedades mecânicas. Apesar de um bom potencial para substituírem os materiais plásticos à base de petróleo, há a dificuldade de se obter este material em escala industrial.

Neste contexto, o método tape-casting permite a obtenção de filmes com maiores dimensões, tendo a sua aplicação industrial. Sendo assim, este material representa uma alternativa para o meio industrial, assim como, para os agricultores que buscam agregar valor ao amido.

Os filmes de acetato de amido não se apresentaram mais resistentes que os filmes de amido nativo. Porém, o fato destes filmes apresentarem menor higroscopicidade, apresentando melhor manipulação, ficando próximo de um material para uso geral.

A orientação da matriz no momento da elaboração do material não teve diferença significativa sobre a resistência do material. Isto é interessante, pois mostra que o material formado é homogêneo e uniforme.

\section{REFERÊNCIAS BIBLIOGRÁFICAS}

ANVISA, Agência Nacional de Vigilância Sanitária. Disponível em: http://www.anvisa.gov.br/legis/resol/12_78_amidos.htm

AOAC. Association of Official Analytical Chemists. Official methods of analysis of AOAC 5 International. 16.ed., v.2. Arlington:AOAC, 1995.

BRASIL - MAPA. Ministério da agricultura, pecuária e abastecimento. Site: www.agricultura.gov.br. Acesso em: 30/08/2013. 
COVA, A.; SANDOVAL, A.; BALSAMO, V.; MÜLLER, A.J. The effect of hydrophobic modifications on the adsorption isotherms of cassava starch.

Carbohydrate Polymers, n.81, p. 660-667, 2010.

GONTARD, N.; GUILBERT, S.; CUQ, J. L. Water and Glycerol as Plasticizers Affect Mechanical and Water Vapor Barrier Properties of an Edible Wheat Gluten Film. Journal of Food Science, Chicago, v.58, n.1, p. 206-211, 1993.

WILHELM, H.M.; SIERAKOWSKIA, M.R.; SOUZAB, G.P.; WYPYCHC, F. Starch films reinforced with mineral clay. Carbohydrate Polymers, v. 52, p. 101$110,2003$.

McCREADY, R.M.; HASSID, W.F. The separation and quantitative estimation of amilose and amylopectin in potato starch. Journal of the American Chemical Society, 65, 1154, 1943.

MORAES, J. O. Propriedades de filmes de amido incorporados de nanoargilas e fibras de celulose. Dissertação (Mestrado) - Universidade Federal de Santa Catarina,Centro Tecnológico (CTC). Florianópolis, 2009.

MORAES Produção e caracterização de filmes de amido-glicerol-fibras de celulose elaborados por tape-casting, 2013.

WILLIAMS, P.C.; KUZINA, D.F.; HLINKA, I.A. Rapid colorimetric procedure for estimating the amylose content of starches and flours. Cereal Chemistry, v. 7, n. 197, 412-420, 1970.

SCHEIBE, ANA S.; DE MORAES, JAQUELINE; LAURINDO, JOÃO B. . Production and Characterization of Bags from Biocomposite Films of Starch-Vegetal Fibers Prepared by Tape Casting. Journal of Food Process Engineering ${ }^{\text {JCR }}$, v. 1, p. n/a-n/a, 2012. 


\section{Congresso Brasileiro de Engenharia Química em Iniciação Científica UFSCar - São Carlos - SP

SCHMIDT, Vivian Consuelo Reolon ; PORTO, Luismar Marques ; Laurindo, João Borges; Menegalli, Florência Cecília . Water vapor barrier and mechanical properties of starch films containing stearic acid. Industrial Crops and Products (Print), v. 41, p. 227-234, 2013 
